\title{
The Current Context for Science, Society and Public Policy
}

\author{
Alan I. Leshner, Ph.D. ${ }^{1}$ \\ Chief Executive Officer \\ American Association for the Advancement of Science \\ Executive Publisher, Science
}

\begin{abstract}
A s with all human activities, science is not conducted in a vacuum, and the way 1 its products are used is determined to a large degree by the broader societal context in which the scientific enterprise is imbedded. That context is determined by three major factors: issues arising within science itself; government regulations, priorities and funding patterns; and the broader and changing relationship between science and the public.
\end{abstract}

\section{Major trends within science}

Advances in science are coming at an ever-accelerating pace, in part because of major changes occurring in the way the scientific enterprise is organized and operates. For example, so-called "big science" team research was historically only a characteristic of a subset of the physical sciences, where people have to work together and share resources on projects such as those involving accelerators or telescopes. Conversely, the life sciences operated only in the "individual investigator" mode: A laboratory director might have a few graduate students and post-doctoral associates, but each established scientist fundamentally functioned as his or her own enterprise. The advent of the Human Genome Project (HGP), however,

1. Mailing address: AAAS, 1200 New York Ave., NW, Washington, DC 20005; aleshner@aaas.org marked a major shift for the life sciences. Completing the HGP required team work on an unprecedented large scale. We now are seeing more and more team projects like those in proteomics or in sequencing the genomes of other species.

A second major trend affecting the way science is organized and carried out is the increasing multi-disciplinarity of many of the most interesting and challenging scientific questions. For example, getting answers to virtually all of the 125 great, unanswered questions identified recently in the journal Science ${ }^{2}$ (the list begins with "What is the Universe made of?") will require that scientists work across traditional disciplines. In fact, many people believe we are beginning to see the demise of traditional disciplinary research and of

2. 125 Questions: What Don't We Know? Science, 2005: Vol. 309, 1-204. 
disciplines themselves. This will become highly problematic if we continue to try to maintain our traditional disciplinary departmental structures in universities and funding agencies.

The third major trend within science is that rapid advances in technology are now enabling entirely new kinds of questions to be asked. Many of us were taught originally that the normal sequence of events is that scientific advances lead to new technologies, which then lead to applications. We now are seeing that technology is driving science as much or more than the reverse. Examples are easy to find. Those in my own fields include how brain imaging techniques are enabling us for the first time to look into the brains of living, awake, behaving human beings and observe their minds in neurobiological action. This ability is revolutionizing the ways we can study mind-body relationships. It also is revolutionizing our fundamental understanding of the processes underlying such important human characteristics as mental disorders and addiction.

New technologies are also expanding how we view the processes of research. Most of us were taught that we begin any scientific investigations with a clear hypothesis, which we then test systematically. In fact, it has long been very difficult to get a grant without a clear hypothesis stated right in the beginning of the proposal.

But now, new technologies, like gene arrays, are enabling us to collect large amounts of descriptive information that we will only know how to interpret after the data are analyzed. This kind of an approach-and gene arrays in particular - has been extremely important in understanding which biological systems are worth investigating further in a variety of complex areas, again including addiction and mental disorders. The grant review process, however, has been slow to catch up with the trend, and it still is very difficult to get funded for these kinds of studies.

\section{Trends in government regulations, priorities and funding}

The events of September 11, 2001, resulted in major changes in both the context and priorities for American science. The most visible impact was the dramatic set of changes related to international travel-primarily for nonUS citizens coming into the United States, but also for Americans going abroad. New, complicated visa processes put in place after 9/11 have caused dramatic reductions in the numbers of foreign graduate students and scientists both able to attend conferences in the United States and joining the American scientific student and work forces. Table 1 shows the results of a Council of Graduate Schools Survey, and illustrates the dramatic reductions in international graduate applications post $9 / 11 .^{3}$

The events of $9 / 11$ were also followed by a dramatic shift in national research priorities toward issues related to individual and national security. Wholly new research emphases appeared and received tremendous amounts of Federal government support. These included bioterrorism, transportation security, cybersecurity, and safety of the

3. Brown, H.A. and Syverson, P.D. Findings from U.S. graduate schools on international graduate students admission trends. Council of Graduate Schools, September 2004. 
food supply-all areas that had received little or no government attention before. This shift in priorities was also reflected, of course, in much smaller increases in funding being provided for more traditional areas of research. A full description of these trends over the past few years in Federal funding can easily be found at: http://www.aaas.org/spp/rd/.

\begin{tabular}{|r|c|c|}
\hline \multicolumn{3}{|c|}{ Table 1: Trends in International Graduate } \\
Applications, 2003-2004 and 2004-2005 \\
\hline & $\begin{array}{c}\text { Application } \\
\text { Change } \\
2003-2004\end{array}$ & $\begin{array}{c}\text { Application } \\
\text { Change } \\
2004-2005\end{array}$ \\
\hline $\begin{array}{l}\text { U.S. Domestic and } \\
\text { Permanent }\end{array}$ & $0 \%$ & $-1 \%$ \\
\hline Resident & $-28 \%$ & $-5 \%$ \\
\hline International & & $-13 \%$ \\
Country of Origin & $-45 \%$ & $-9 \%$ \\
India & $-28 \%$ & $0 \%$ \\
Korea & $-14 \%$ & $+6 \%$ \\
Middle East & $+4 \%$ & $-8 \%$ \\
Business & $-24 \%$ & $-3 \%$ \\
Education & $-21 \%$ & $-7 \%$ \\
Engineering & $-36 \%$ & $+2 \%$ \\
Humanities & $-17 \%$ & $-1 \%$ \\
Life Sciences & $-24 \%$ & $-3 \%$ \\
Physical Sciences & $-22 \%$ & $-4 \%$ \\
Social Sciences & $-20 \%$ & \\
\hline
\end{tabular}

\section{The changing relationship of science and society}

A vibrant science and technology (S\&T) enterprise is central to the success of every developed country, since most productivity and new product gains are traceable at least indirectly to advances in S\&T. Moreover, those countries lacking strong scientific infrastructure appear doomed to lag behind their counterparts with strong science. By now, science and technology are imbedded in virtually every aspect of modern life, and thriving in that environment requires that individuals have reasonable comfort and knowledge about S\&T and their products.

The relationship between science and American society has traditionally been a good one; a large majority of the citizenry recognizes that the benefits of scientific research far outweigh its risks. In fact, the percentage of Americans who see S\&T as fundamentally positive has remained above $70 \%$ since at least the mid-1970s. ${ }^{4}$ This contrasts with the European Union, where there have been significant declines in public appreciation of science over the past decade or more.

This optimistic view of U.S. attitudes toward science is somewhat overstated, since at the same time that Americans seem to value science, they do not really understand what is and is not science. For example, $60 \%$ believe in extrasensory perception; $41 \%$ think astrology is somewhat scientific; $47 \%$ do not answer "true" to the statement "Human beings developed from earlier species of animals." 5

Although the overall relationship remains positive, many are reporting that aspects of the science-society relationship are deteriorating. There appears to be a significant increase in the politicalization of science and its findings, and overall

4. Data on the American public's understanding and views of science and technology have been extensively reported in the National Science Board's biennial Science and Engineering Indicators. Attitudes in the European Union have been reported in the European Commission's Eurobarometer 2005 report.

5. National Science Board, Science and Engineering Indicators, 2004. 
confidence in science appears to be eroding.

A major contributor to this recent trend is the addition of a new dimension in the relationship between science and society. Whereas historically, S\&T have been evaluated primarily on the basis of their relative costs and benefits, we now are seeing S\&T evaluated in terms of the way their products relate to core human values as well. A well-known example of values considerations being overlaid onto the scientific agenda is the domain of embryonic stem cell research. People's positions on the acceptability of this line of research are heavily influenced by their views of when life begins-at conception, embryo implantation, birth. A second example was provided by a recent attempt by some members of the U.S. House of Representatives to de-fund four NIH grants whose focus on sexual behavior made those members of Congress uncomfortable. ${ }^{6}$

A dramatic example is the attempts to insert the teaching of creationism or "intelligent design" (ID) into the science curriculum as a purported scientific alternative to evolution. ID advocates argue that although humans may have developed from lower organisms gradually over billions of years, that process had to have been guided by a supernatural force, an "intelligent designer," since they cannot conceive of complex organisms and biological systems developing through random mutation and environmental adaptation. They label ID a scientific alternative to evolution and claim therefore that it

6. A transcript of the Congressional floor debate on this issue is available at http://www.apa.org/ ppo/issues/nihtoomevdebate.html. should be taught as a controversy in science classrooms. This not only would introduce a fundamentally religious concept into the science curriculum, but would pit religion and science against each other.

The core problem is that intelligent design is neither a science-based nor a scientifically testable concept. The accepted methods of science-direct observation, experimentation, systematic measurement, replication-cannot be applied to the question of whether there is or was an intelligent designer. Moreover, scientific explanations are limited to the natural world. Therefore, we in the scientific community object to any reference to ID as being scientific. We cannot allow people to redefine science for their convenience or to fit their ideologies. Moreover, we do not want to lead young people astray by teaching them non-scientific facts and theories as if they were scientific. ${ }^{7}$

The primary consequence of this new overlay of values onto science is substantially increased tension between science and segments of society. That tension is being expressed in a variety of ways, including increased attempts by the public and policymakers to shape or modify the research agenda. Whereas we traditionally think of science and technology as having influenced the course of civilization and the overall status of society, we now are seeing more and more attempts by the public to influence the course of science. Members of the public want to help frame the research agenda, including at times

7. Leshner, A.I. Redefining science. Science 2005: $309,221$. 
deciding what can and cannot be studied.

This values-related tension, when combined with some other factors, is creating a widening divide between science and society. ${ }^{8}$ Those other factors include a misunderstanding about the meaning to scientists of the word "theory," which is different from the popular view that a theory is simply an educated guess. This becomes an issue when, for example, the intelligent design advocates claim it to be a "theory" just like the theory of evolution. Of course, evolution is supported by thousands of observations and studies and certainly is substantially different from an educated guess or a belief per se, as is intelligent design.

Another major contributing factor is the assumption by scientists that scientific illiteracy on the part of the public is the central cause of the tension, and that the problems can be solved simply by educating the public better. The problem, however, is not just lack of understanding. Often, the public does understand the science, and they just do not like what it is showing or what it means. The case of embryonic stem cell research is an excellent case in point. Here there is genuine disagreement about when life begins, and stem cell opponents-many of whom understand well the nuances of embryos, blastocysts, implantation and other scientific concepts - simply do not agree that any embryos should be sacrificed for the sake of any research.

8. Yankelovich, D. Winning greater influence for science. Issues in Science and Technology, Summer 2003.

\section{Bridging the divide-from public understanding to public engagement}

How can we reduce the tension in the science-society relationship and forestall any further deterioration? Our approach so far has been primarily to rise up in protest any time the integrity of science and its products is threatened, and I do believe we need to continue to do that. We cannot allow anyone to redefine science or to misinterpret scientific findings for their convenience. The scientific enterprise needs to be the principal guardian of the scientific method, including insisting on peer review before publication/publicity and conveying the appropriate caveats as findings are discussed publicly.

Simply protesting violations of our norms will not do it alone. In the same way that we cannot simply educate our way out of these dilemmas, neither can we lament our way out. I believe the only way to move forward is to engage in a much more open and genuine dialogue with the public about science in general and about specific scientific findings in particular. We need to move from what might be thought of as a public understanding model into a true public engagement model.

We need to move from what many have experienced as a paternalistic monologue by the scientific community directed at the public, into a true multidirectional dialogue that involves listening as well as speaking. We need to hear from the public about their concerns about science and technology - how they see the risks and benefits, and how they experience the encroachment of science onto human values. We need to listen to the public's priorities among research 
areas, and we need to hear the questions the public would like us to answer so they can make more informed decisions. In short, we need to allow the public to help shape the research agenda. By this, I do not mean to list areas that are permissible to study and those that are not. I do mean that the public should be allowed to pose questions for science, and that we need to respond.

Does the public want to be engaged in this way? No systematic surveys have been conducted in the United States, but we know that many people do read the science news in their local newspapers, and more general attitude surveys do show high levels of interest in science.

A relevant survey of the public's interest in greater engagement with science was conducted in the United Kingdom and reported in March $2005 .{ }^{9}$ Results included the findings that:

- $74 \%$ of people say they ought to hear about potential new areas of science and technology before they happen;

- $81 \%$ say the public should be consulted on decisions about scientific developments;

- $51 \%$ would be interested in taking part in a national debate on science-related issues;

- $79 \%$ say that scientists should spend more time discussing the implications of their work in public;

- $75 \%$ think scientists should listen more to what ordinary people think.

What to do? How should we go about engaging with the public? Ruth Wooden, President of Public Agenda, a non-profit organization that specializes in engaging with the public on a wide

9. Office of Science and Technology, UK Department of Trade and Industry, Science in Society, March 2005.

10. Wooden, R. Remarks during the annual meeting of Research! America, 2004. variety of societal issues, advises against some of our traditional approaches. ${ }^{10}$ She suggests it is actually counter-productive to simply hold a series of public education events where scientists pontificate in jargon-laden terms to "educate" the public. She also advises against large town meeting types of forums, where the extremists on both sides of the issue dominate the conversation but never reach any common ground. Public Agenda advocates small group formats, where the groups are asked to work through specific questions and options for resolving issues, looking for areas of common ground.

Some groups are working in this mode already. Many of the projects supported by the National Human Genome Research Institute's program on Ethical, Legal and Social Implications (ELSI) use small group engagement approaches. AAAS's Dialogue on Science, Ethics and Religion brings together scientists, ethicists and religious leaders to discuss issues of common concern. A third example is the Genetics and Public Policy Center at Johns Hopkins University, which considers issues at the interface of genetic research and public interest/concern.

AAAS is in the process of developing a new programmatic center whose focus will be public engagement with science and technology. The notion is to use a combination of approaches both to engage the public and to defend the integrity of science and the use of its products. 


\section{Concluding comments}

As I look at the evolving relationship between science and society, I am reminded of that ancient curse "May you live in interesting times!" The science has never been better, and our enterprise has never been stronger. On the other hand, the science-society relationship is more tense than ever in my professional life. From a historical perspective, the strain we now are experiencing may not really be new. The tension level between science and society has increased many times in the past, typically when scientific findings abut against values questions like the essence of our humanity, our place in the universe, or when life begins, or when scientific findings conflict with political expediencies.

Whether we are experiencing a new trend or a recurrent cycle, the sciencesociety relationship is in great need of attention. And we will need to adopt a new strategy to repair it. We will not be able to simply educate our way out of the problem, because its essence is not simply lack of public understanding. As mentioned before, many people do understand what the science is showing; they just do not like it. Moreover, in contrast to scientists, most people in the community do not feel bound to stick to what the science is showing.

I believe the only viable approach as we move forward is to do a much better job of engaging the public, in true dialogue about their concerns and how they might be addressed. I am not so naïve as to suggest that we try to convert the ideologues on either side of controversial issues. But the majority of people are not ideologues, and we should be able to find meaningful common ground that will allow science to do its best at its principal task-advancing society and improving the human condition. 